\title{
O PAPEL DOS GÊNEROS DISCURSIVOS ESCRITOS NA AQUISIÇÃO DO PORTUGUÊS POR FALANTES SURDOS: ALGUMAS IMPLICAÇÕES
}

\section{THE ROLE OF DISCURSIVE WRITTEN GENRES IN THE ACQUISITION OF PORTUGUESE BY DEAF SPEAKERS: SOME IMPLICATIONS}

\author{
Walison Paulino de Araújo Costa ${ }^{1}$ \\ Universidade Federal Rural de Pernambuco \\ Lucineudo Machado Irineu ${ }^{2}$ \\ Universidade Estadual do Ceará
}

\section{RESUMO}

Este texto traz uma discussão em torno da educação surda, mais especificamente a questão do português escrito como segunda língua para os surdos falantes de LIBRAS (Língua Brasileira de Sinais). Nossos objetivos se materializam da seguinte forma: discutir o relevante papel dos gêneros discursivos em geral, em meio à aquisição da segunda língua, sobretudo quando consideramos o fato de que vivemos em um mundo plural de semioses e letramentos, e discutir como os gêneros digitais, em questões mais ligadas à função do que à forma, podem ajudar o falante surdo a aprender a língua portuguesa, possibilitando-lhe ser inserido em um universo letrado como usuário proficiente e interativo. Em termos metodológicos, procedemos à discussão através de uma análise qualitativa, articulando conceitos, noções e categorias trazidas pela incursão na literatura especializada, com base em: Cavalcanti \& Silva (2007), Gesser (2009), Salles et al (2004), Grannier (2007), McCleary (2009), entre outros autores.

PALAVRAS-CHAVES: Educação surda. Português escrito. Gêneros discursivos. Segunda língua

\begin{abstract}
This text discusses the deaf education, more specifically the written Portuguese as a second language for deaf speakers of BSL (Brazilian Sign Language). We aim at discussing the relevant role of text genres in general amongst the acquisition of a second language, above all considering the fact that we live within a world full of semioses and literacies; and showing that digital genres, in terms related to function rather than form, can help deaf speakers acquire Portuguese, allowing them to be inserted into a literate world as proficient and interactive users. In methodological terms, our discussion took place through a qualitative analysis, which provided us with concepts and notions brought from the specialized literature, based on: Cavalcanti \& Silva (2007), Gesser (2009), Salles et al (2004), Grannier (2007), McCleary (2009), among others.
\end{abstract}

KEY WORDS: Education. Written Portuguese. Discursive genres. Second language

\footnotetext{
${ }^{1}$ Professor do Curso de Letras/Inglês da Universidade Federal Rural de Pernambuco (Unidade Acadêmica de Serra Talhada). Doutor em Linguística pela Universidade Federal da Paraíba. E-mail: walliecoast@yahoo.com.br

2 Professor do Curso de Letras/Espanhol e do PROFLETRAS da Universidade Estadual do Ceará (Campus Fátima). Pós-doutor em Linguística pela Universidade Federal do Ceará. E-mail: lucineudomachadoirineu@gmail.com
} 


\section{INTRODUÇÃO}

Estamos vivendo um momento em que as fronteiras geográficas se encurtam cada vez mais ou tendem a desaparecer. Essa tendência se dá em função de um fenômeno chamado globalização, em meio ao qual faz emergir uma sociedade da informação, a princípio como uma espécie de promessa que pode ser acessada ${ }^{3}$ por todos. Sob um olhar mais cauteloso, contudo, pode também ser promotora, muitas vezes, da exclusão e da segregação multiforme de diversos grupos. Nesse contexto, novas categorias conceituais se espraiam, tais como local/global, aldeia global etc. Outros valores passam a orbitar os espaços sociais, portanto. Em função dessas reconfigurações epistemológicas e da reconceitualização do mundo em nossa volta, as noções em relação às questões de variação linguística, línguas de contato, políticas de reconhecimento linguístico, questões identitárias, questões culturais e outras que extrapolam a língua, como limites de espaços nacionais, ações de inclusão, políticas em favor das minorias, têm alcançado outros vieses, por meio das quais tem ficado cada vez mais fácil visualizar a emergência da atenção que deve ser dispensada aos direitos fundamentais, tão aclamados desde a Declaração Universal dos Direitos Humanos, de 1948. Não é à toa que é mencionada no próprio corpo desse texto, no artigo II (ONU, 2013, p. 27), a seguinte afirmação:

Todo ser humano tem capacidade de gozar os direitos e as liberdades estabelecidas nesta Declaração, sem distinção de qualquer espécie, seja de raça, cor, sexo, idioma, religião, opinião política ou de outra natureza, origem nacional ou social, riqueza, nascimento, ou qualquer outra condição.

Por outro lado, o próprio conceito de democracia, herdado pelo mundo grego, vem sofrendo ressemantização, hasta vista sua desvinculação da ideia de "maioria": antes, a democracia era vista como sendo constituída pela maior parte; hoje, esse conceito evoluiu, trazendo uma concepção que, em hipótese nenhuma, silencia as "minorias". Em outras palavras, as minorias também devem ser levadas em conta: homossexuais, negros, indígenas, imigrantes, entre outros, os portadores de necessidades especiais. Nesse compasso, vemos um avanço das discussões nos diversos campos do saber, entre os quais mencionamos a Linguística Aplicada, enquanto grande área, sobretudo quando optamos por uma discussão que envolve falantes surdos.

Possivelmente, em outros tempos, seria uma afirmação falaciosa referir-se a um "surdo falante". Entretanto, em função dos estudos e pesquisas que vêm se desenvolvendo acerca desses sujeitos e de todo seu universo de competências e habilidades linguísticas, como por exemplo, as investigações de Campello (2008), Nascimento (2008), Agrella (2010), Barbosa (2010), Hahn (2012), devemos reorientar nosso pensar e, principalmente, nossa agir em relação ao fato de que se trata de indivíduos que se comunicam como quaisquer outros, os quais, quando têm oportunidade de acesso, utilizam a LIBRAS - Língua Brasileira de Sinais - como primeira língua, assim como a maioria dos brasileiros utiliza o português, além, é claro, de serem capazes de aprender uma segunda língua, seja o português ou quaisquer outras línguas, desde que, para isso, haja metodologia adequada, como bem pontua Grannier (2007).

Nesse sentido, vemos que o português para os falantes surdos se apresenta como uma possível segunda língua, mesmo que esses, desde o nascimento, vivam no território brasileiro. Quando pensamos no ensino formal da língua portuguesa para os surdos, obrigatoriamente devemos pensar nas finalidades de ler e escrever, tendo em vista que se trata da língua oficial no Brasil e, portanto, é a língua por meio da qual todos os documentos oficiais são redigidos e as

\footnotetext{
3 A ideia de acesso aqui se deve, sobretudo, à concepção de acesso virtual, da qual pegamos emprestado para dimensionar a questão da rede de informações que nos são apresentadas dia a dia. É o termo mais apropriado que encontramos para designação dessa nova ordem.
} 
comunicações entre indivíduos se dão cotidianamente. Dessa forma, vemos que a aprendizagem da referida língua só aumenta a possibilidade de os surdos terem acesso aos bens culturais brasileiros e de todo o resto da lusofonia no mundo.

Há bem mais de uma década a questão dos gêneros discursivos, no quadro dos estudos linguísticos, tem suscitado implicações tanto para o ensino da primeira língua ${ }^{4}$ quanto para o ensino da segunda língua. Novas concepções sobre a língua, novas formas de ensiná-la, de aprendê-la estão em pauta, uma vez que não faz mais sentido ensinar uma determinada língua exclusivamente pela prescrição de regras da gramática padrão, por exemplo. Afinal, como diz Antunes $(2005$, p. 11) ser usuário de uma língua “[...] depende de outros fatores que não aqueles puramente internos à língua. A língua enquanto sistema de formas não comanda tudo". A tendência a ser seguida deve ser sempre com foco no texto, o mais autêntico possível, de maneira que a finalidade de aprender uma dada língua seja, em termos gerais, o manuseio, via recepção e produção, dos gêneros discursivos que circulam no universo social desses sujeitos aprendentes. Referimo-nos aos gêneros enquanto tipos relativamente estáveis de enunciados constituídos social e historicamente, conforme assinala Bakhtin (1992). Dessa forma, ao abordar a questão da aquisição do português, queremos saber até que ponto os gêneros podem desempenhar papel de destaque nesse processo de aprendizagem/aquisição pelo surdo.

A outra questão tratada neste trabalho refere-se aos domínios teóricos estabelecidos entre aquisição e aprendizagem. Grosso modo, optamos pelo termo aquisição, tendo em vista que o contato do surdo com a língua portuguesa, via de regra, se dá de maneira direta: em casa, entre familiares e amigos, na rua, em diversas situações do cotidiano, onde geralmente estão também inseridos falantes ouvintes do português. Porém, esse contato direto não implica uso consequente da língua, tendo em vista que ao surdo não é possibilitado adquirir as línguas oral-auditivas de forma simples e natural, como ocorre com os ouvintes. Por outro lado, em outras situações, utilizamos o termo aprendizagem, visto que, somente na escola, a aprendizagem, no sentido estrito, passa a existir. Entendemos que lá são transmitidos conhecimentos sobre a segunda língua, no caso, a língua portuguesa e sobre a própria LIBRAS.

\section{O surdo e a surdez: uma breve história e sua relação com a escola brasileira}

De acordo com McCleary (2009), por muito tempo, houve a crença de que, para adquirir/aprender uma língua, era preciso lançar mão da audição e das habilidades relacionadas à oralidade. Por esse motivo, os surdos eram considerados inaptos para desenvolver o pensamento abstrato, restando-lhes o degredo e o status categórico como sujeitos patológicos.

Seguindo a cronologia na literatura especializada, em conformidade com Salles et al (2004), na Grécia e na Roma antigas, a esses indivíduos custava a própria vida pelo fato de serem surdos. Acreditava-se que os surdos eram culpados pela condição que lhes era conferida. Durante muito tempo, esses sujeitos sofreram preconceito de toda sorte, sendo, em muitas situações, tidos como loucos ou merecedores de piedade.

Conforme os mesmos autores, em 637 d. C., o bispo John of Bervely ensinou um surdo a falar com clareza, o que, na época, foi concebido como um milagre. Já no século XVIII, surgiram os pioneiros na educação de surdos, criando metodologias diversas. Entre eles, podemos mencionar: o alemão Samuel Heineck, o abade francês Charles Michel de L'Epée e o inglês Thomas Braidwood. Na França, o português Jacob Rodrigues Pereira desenvolveu um método, por meio do qual ensinava a fala aos surdos, atividade que era seguida de exercícios auditivos.

\footnotetext{
${ }^{4}$ Utilizamos "primeira língua" em vez de "língua materna", uma vez que a língua dos pais dos surdos, normalmente, por serem ouvintes, é o português. Já para a criança surda, a LIBRAS, via de regra, é a primeira língua.
} 
No Brasil, com a chegada do francês Ernest Huet, em 1855, foi criada uma escola exclusivamente para surdos, o que se supõe ter sido um avanço para a época, momento em que os surdos não eram considerados cidadãos.

Em 1880, depois do Congresso Internacional de Surdo-Mudez, em Milão, na Itália, o método oral ficou consagrado. Lamentavelmente, mesmo tendo evoluído desde as civilizações clássicas, particularmente na Grécia e em Roma, a surdez passou a ser vista dentro de uma ótica eminentemente clínica, pois não era conferida ao sujeito surdo a capacidade da abstração. Por essa razão, houve muitas tentativas de "curar" o surdo, de trazê-lo a um estado de recuperado.

A modalidade oral, nessa perspectiva, deveria ser privilegiada, assim tornando o uso dos sinais atitude que representava a condenação do sujeito surdo para viver imerso numa então considerada "subcultura" . A partir desse referido congresso em Milão, passou-se a rejeitar cada vez mais o gestualismo, restando, como única saída, fazer com que o surdo viesse a superar a "deficiência" isto é, uma tentativa de formar uma espécie de homogeneidade em relação às comunidades majoritárias e, consequentemente, dominantes.

Numa outra perspectiva, de forma geral, as sociedades ocidentais são marcadamente grafocêntricas, o que nos impulsiona a afirmar que a escrita, de alguma forma, rege a vida das pessoas, notadamente o seu universo escolar. Dessa forma, observamos que a escola ainda, lamentavelmente, lida com a escrita fora da concepção que a vislumbra como prática social.

Ao contrário, A escola, em termos gerais, numa perspectiva tradicional, trata da escrita como se ela fosse exclusivamente a ortografia e a gramática fora do texto. Antunes (2005, p. 10) defende que, do ponto de vista teórico, "[...] a língua não se acha confinada às regras da gramática, nem é uma questão de certo e errado, mas é uma atividade social que cria as condições da interação e dos processos comunicativos em geral". E é exatamente essa atividade social a que nos referimos quando fazemos emergir uma discussão em torno do ensino da língua portuguesa para surdos por meio, principalmente, dos gêneros textuais escritos.

É nesse sentido que devemos refletir sobre uma escola que não encontra espaço para alunos que utilizam um português que não seja padrão. Pior que isso é saber que ela não está preparada para receber alunos provenientes de contextos tão plurais e heterogêneos, como é o caso das minorias linguísticas existentes na grande extensão territorial do Brasil. A esse respeito, estamos nos referindo às línguas indígenas existentes; às línguas faladas pelos filhos e descendentes de imigrantes; às línguas miscigenadas, usadas por falantes que moram nas cidades fronteiriças com países vizinhos. Tampouco há espaço, nas referidas escolas, se pensarmos utopicamente em um mundo de políticas públicas eficazes, para indivíduos portadores de alguma necessidade especial, entre os quais, por exemplo, mencionamos os surdos.

Segundo Cavalcanti \& Silva (2007), a democratização do ensino, na década de 1920, foi a primeira tentativa com relação à proposta de inclusão nas escolas públicas. Nessa escola, porém, nunca houve espaço para alunos com necessidade especiais. Na verdade, essa tentativa foi vã, uma vez que em nada a escola brasileira, neste momento específico, trouxe resultados positivos. Apenas promoveu mais exclusão, até mesmo a dos indivíduos ditos "normais", já que quem não era considerado apto para acompanhar todo o processo de aprendizagem, automaticamente entraria no percentual que constituía a crescente evasão escolar da época.

Para os portadores de necessidades especiais, a saída eram as escolas mantidas pela filantropia ou o Instituto Nacional de Surdos, que acolhia alunos do Brasil e da América Latina desde 1857, no Rio de Janeiro. Já em São Paulo, a partir de 1933, começou a atuação do Instituto Santa Terezinha. Somente depois de 1950, passam a existir as primeiras iniciativas do município e

\footnotetext{
${ }^{5}$ Contemporaneamente, a concepção reinante é totalmente oposta a essa de subcultura, ou seja, concebemos que os surdos, assim como os ouvintes, possuímos múltiplas identidades e culturas. Assim, definitivamente, não cabe mais a referência à "subcultura", a não ser para efeito de registro meramente histórico. (GESSER, 2009)

${ }^{6}$ Do ponto de vista cultural, a surdez não é considerada "deficiência", como veremos mais adequadamente em seção própria.
} 
de pais de crianças surdas, que resultam na criação do Instituto Helen Keller e do Instituto Educacional São Paulo. Em São Paulo, a rede estadual criou cinco salas especiais para atender a alunos surdos em 1957.

$\mathrm{Na}$ década de 1990, percebemos alguma mudança nesse cenário educacional, pois aqueles que antes eram "invisíveis" passaram a ser mencionados (não podemos dizer inclú́dos!), tendo em vista que, para a escola regular, eles eram um "problema" a mais. Ou seja, deveriam usar a língua portuguesa nas modalidades oral e escrita assim como faziam os alunos ouvintes, visto que as aulas das diversas disciplinas eram (e ainda são, em muitos casos) ministradas apenas em português. Obviamente, não tinham como acompanhar esse ritmo. Diferentemente dessa realidade, os surdos deveriam estar numa situação pelo menos bilíngue, sendo acompanhados por professores proficientes tanto em português quanto em LIBRAS.

Em referência à legislação que trata desta questão, a partir de 1988, podemos contar com o artigo 205 da Constituição Federal cujo teor afirma que todos aqueles que tiverem necessidades especiais devem ser atendidos preferencialmente na rede regular de ensino. A partir de 1996, passou a existir a Lei de Diretrizes e Bases, a conhecida LDB, segundo a qual, de "preferencial" passou a ser obrigatória a inclusão de todos os alunos na rede regular de ensino. Lamentavelmente, mesmo com tamanha incisão, a Lei não conseguiu resolver o velho problema na inclusão, pois a mudança só se deu textualmente. O insucesso da LDB podia ser visto pela repetência e pela evasão escolar. O que isso veio a sinalizar? Não houve uma reflexão e consequente mudança no currículo, na formação de professores, somente com os quais o acesso à escola dessa população diferente poderia ter de fato acontecido e realmente dado certo. Contudo, de uns anos para cá, a partir do Decreto 5.626, de 22 de dezembro de 2005, que regulamenta a Lei 10.436, de 24/04/2002, o ensino de LIBRAS passou a ser obrigatório para os cursos de licenciatura.

No entanto, ainda não alcançamos a desejada inclusão, pois ainda, nas escolas da rede regular de ensino, os professores, em sua maioria, não falam LIBRAS, independentemente de serem ouvintes ou não. Dessa forma, ainda detectamos que há mitos com relação ao binômio surdez/escolarização, além da falta de formação de professores adequada para lidar com os alunos surdos, fazendo com a escola ainda esteja despreparada para receber os alunos surdos.

Em obediência à ordem na seção apresentada, esta parte que começaremos agora, referente ao surdo e à surdez, deveria ter vindo no início da discussão, porém, propositalmente, falamos da história da surdez e sua relação com a escola brasileira, para, posteriormente, tratar de questões mais conceituais ligadas ao fenômeno da surdez, e como consequência, do surdo, não necessariamente nessa mesma sequência, trazendo à tona alguns aspectos que podem se apresentar como mitos para a maioria das pessoas, e que, por serem mitos, merecem ser esclarecidos com muita urgência.

Segundo Gesser (2009), faremos as seguintes ponderações sobre a realidade da surdez e sobre quem a vivencia. Logo de início, colocamo-nos a pensar: como devemos nos referir a esses cisujeitos? Que termo devemos usar para referenciá-los? Parece-nos, num primeiro instante, que o termo "surdo" sugere algo pejorativo, imbuído de um claro preconceito, porém, é o mais acertado, mais aceito e menos ofensivo entre aqueles que constituem a comunidade de surdos e ouvintes usuários de LIBRAS. Existem outros termos que devemos rejeitar: mudo, surdo-mudo, deficiente auditivo.

Os termos mudo e surdo-mudo carregam em si bastante preconceito, pois os indivíduos a que nos referimos, os surdos, possuem aparelho fonador, razão por que podem perfeitamente ser treinados para oralizar, segundo relato de um professor surdo. Além disso, eles podem não falar a língua portuguesa, mas, se tiverem acesso à aprendizagem formal da língua de sinais, serão preservadas suas faculdades linguístico-cognitivas, retirando-lhes de uma vez por todas a pecha relacionada à mudez, conceito errôneo comumente impregnado num ou noutro termo acima. $\mathrm{O}$ termo deficiente auditivo foi criado pela visão patologizante, segundo a qual a surdez deve ser 
rechaçada, e o ouvintismo ${ }^{7}$, restabelecido. Sua criação, na verdade, é fruto do discurso autoritário da medicina.

O termo, como dito antes, mais apropriado é surdo, pois o sujeito pode até aprender a oralizar (ou, como muitos desejam, falar), porém a surdez permanece. Nem por isso, é possível privá-los da prerrogativa de falante, uma vez que quaisquer sujeitos surdos podem ser usuários da língua de sinais. Nesse dizer, inclusive, há quem pense que o intérprete é a voz do surdo. De fato, o surdo tem voz própria (GESSER, 2009), mesmo que não seja a acústica, à qual a ideologia ouvinte dominante está habituada.

Num primeiro instante, alguns podem pensar que o surdo vive um silêncio obscurantista, posto que essa ideia é veiculada pelo predomínio da cultura que pugna pela imprescindibilidade do som. Entretanto, o que de diferente existe é a ressemantização dos conceitos barulho/silêncio. Esses conceitos legitimamente podem, explicitados os contextos, estar associados a outros sentidos, como a visão, por exemplo.

Em relação à questão cultural, como já afirmamos antes, os surdos possuem múltiplas culturas e identidades, uma vez que entre eles existem índios, negros, mulheres, homossexuais, impedindo-nos assim de negar a acentuada marca de heterogeneidade que constitui tanto ouvintes quanto surdos, indistintamente. Infelizmente, muitos apregoam a falsa crença de que o surdo pode vir a ter dificuldade de escrever porque não sabe a língua oral-auditiva. Muitas são as razões para a sedimentação de tal mito. A escrita é algo que exige esforços tanto de surdos quanto de ouvintes. Porém, o fator de o surdo encontrar maior dificuldade reside no fato de a escrita ter uma relação diretamente ligada à realidade fônica. Além disso, contamos com o trauma que a maioria dos surdos sofreu (e ainda sofre) com a imposição do português em suas experiências escolares, em favor das quais muitos tiveram reprimida a sua língua de sinais. (GESSER, 2009)

Por último, mas não menos importante, interessa-nos fazer menção à questão da leitura labial do surdo. A orientação oralista perdurou na educação surda, o que lhe imprimiu um caráter hegemônico. Porém, atualmente, essa é uma habilidade que, do ponto de vista antropológico, tê-la ou não tê-la não coloca o surdo num lugar de prestígio ou estigmatizado, respectivamente.

Antes de lidarmos diretamente com a questão da língua portuguesa para o surdo, passamos a abordar a questão da surdez, inicialmente, situando-a numa perspectiva completamente oposta à do discurso médico. Contrariamente a essa postura, Gesser (2009, p. 123) destaca que:

\footnotetext{
É importante frisar que os surdos e ouvintes que usam a língua de sinais assumem uma postura positiva da surdez. Em algumas comunidades acadêmicas norte-americanas, por exemplo, já é possível observar uma autonomia identitária, cultural e linguística, e, consequentemente, um senso coletivo crítico de que a surdez como problema é uma construção do mundo ouvinte.
}

A surdez, definitivamente, não deve ser vista como algo negativo, desde que seja assegurado o direito à aprendizagem e ao uso da língua de sinais nos espaços sociais por onde trafega o sujeito surdo. Dessa forma, entendemos que a surdez, dadas as condições que oportunizam o acesso à LIBRAS, não compromete o desenvolvimento cognitivo, tampouco linguístico do sujeito surdo.

Antes de iniciarmos a próxima seção, que trata da questão da LIBRAS e da língua portuguesa, entramos um pouco no cenário que suscita até que ponto o surdo precisa da língua portuguesa para relacionar-se com o mundo em sua volta.

\footnotetext{
${ }^{7}$ Citado por Gesser (2009, p. 64), Skliar (1998, p. 15) diz que "ouvintismo é o conjunto de representações dos ouvintes, a partir do qual o surdo está obrigado olhar-se e narrar-se como se fosse ouvinte".
} 
Primeiramente, por mais que surdo não tenha o português como primeira língua, devemos considerar que ele vive no Brasil, onde ela é a língua oficial. Depreendemos daí que os brasileiros a utilizam, além de suas variantes, em diversas situações, como no trabalho, na escola, em casa, enfim, em espaços públicos e privados em que esses sujeitos estão inseridos. Entretanto, em momento nenhum, devemos crer que o uso do português seja prioritário, sobretudo se a intenção for colocar a língua de sinais em segundo plano.

Precisamos entender que o surdo não conseguirá se desenvolver como um indivíduo em condições normais se não tiver a língua de sinais como sua primeira língua, pois por meio dela ele constrói seu conhecimento de mundo, constitui e fortalece a identidade cultural surda, de acordo com o pensamento de Gesser (2009).

Devemos compreender, por fim, que a língua portuguesa exerce um papel de muita importância na vida escolar e pessoal do indivíduo surdo, porém deve-lhe ser garantido o direito à LIBRAS como primeira língua, realidade que, inevitavelmente, nos impõe a pensar na situação de bilinguismo enquanto possibilidade de a esses sujeitos ser concedido o direito à comunicação de forma legitimada, à expressão, à cidadania, à plenitude como pessoa humana, como discutiremos a seguir.

\section{A LIBRAS e a língua portuguesa: em prol de uma educação surda}

Costumamos imaginar erroneamente que a caracterização das línguas oral-auditivas, como é o caso do português, geralmente se dá de forma totalmente diferente, para não dizer absolutamente oposta, em relação às línguas de sinais, que têm seu referencial na modalidade visual-espacial. Vejamos algumas dessas diferenças. No que diz respeito às línguas de sinais, consoante Salles et al (2004, p. 83), devemos compreender que a constituição do signo linguístico é diferente, se considerarmos as línguas orais uma vez que:

A relação entre significante (imagem acústica/fônica) e significado é arbitrária, isto é, não existe nada na forma do significante que seja motivado pelas propriedades da substância do conteúdo (significado). Uma característica das línguas de sinais é que, diferentemente das línguas orais, muitos sinais têm forte motivação icônica.

As línguas visual-espaciais, quando se articulam com as unidades da substância gestual ou significante, possibilitam "a representação icônica de traços semânticos do referente (significado) [...]" (SALLES et al, 2004, p.83). Contrariamente, considerando as línguas orais, o significante não chama o significado, fazendo-nos, portanto, compreender a arbitrariedade do signo linguístico na modalidade das línguas oral-auditivas. Esse é apenas um aspecto peculiar às línguas visualespaciais. São algumas, de fato, as diferenças encontradas entre as línguas orais e visual-espaciais. Todavia, devemos salientar que motivações de ordem sociolinguística e pragmática, além de aspectos discursivos, também fazem parte das línguas visual-espaciais.

A razão essencial por que há contrastes entre as línguas oral-auditivas e as visual-espaciais se deve ao canal perceptua ${ }^{\beta}$ diverso que elas possuem. Contudo, essa realidade não nos impede de perceber que as línguas de sinais possuem os universais linguísticos encontrados nas línguas orais. Mencionaremos alguns desses universais linguísticos a partir do rol que Salles et al (2004, p. 86) apresentam:

(i) “Onde houver seres humanos, haverá língua (s)" (p. 86)

Em relação a esse primeiro universal, podemos dizer que existem muitas línguas de sinais. No Brasil, temos a LIBRAS, assim como existem outras línguas de sinais nos cinco continentes.

${ }^{8} \mathrm{O}$ canal perceptual refere-se, respectivamente, à audição, nas línguas orais, e à visão, nas visual-espaciais. 
São exemplos: LGP (Língua Gestual Portuguesa), ASL (American Sign Language), LSA (Língua de Sinais Australiana), só para mencionar algumas.

(ii) "Não há línguas primitivas - todas as línguas são igualmente complexas e igualmente capazes de expressar qualquer ideia. O vocabulário de qualquer língua pode ser expandido a fim de incluir novas palavras para expressar novos conceitos" (p. 87)

Um exemplo para esse universal é o sinal equivalente a e-mail. Sabemos que em função da recente onda tecnológica, muitos termos são criados entre as línguas, entre as quais se incluem as visual-espaciais.

Assim como as línguas oral-auditivas, as visual-espaciais também podem ser aprendidas por quaisquer crianças de qualquer lugar do mundo, desde que, para isso, tenham sido expostas a ela desde sua mais tenra idade.

Vemos alguns desses universais linguísticos e, de fato, é de perceber que as línguas de sinais não podem ser relegadas a um plano secundário. Primeiramente, como já dito antes, se trata da língua através da qual as identidades e a culturas surdas são constituídas. E, em segundo lugar, porque a elas deve ser conferida uma espécie de isonomia em relação às línguas oralauditivas.

No que diz respeito ao ensino da língua portuguesa, as questões a serem abordadas devem ser outras. De alguma forma, essa língua, vista a partir da perspectiva da realidade surda, soa como a língua dominante que, via de regra, exclui a comunidade surda. Isso ocorre principalmente pelo fato de o canal perceptual dos surdos ser outro: a visão. Dessa maneira, é racional e lógico não esperarmos de um sujeito surdo que ele consiga obter êxito em situações de aprendizagem com o português oral, como acontece com os ouvintes. E aí, óbvio, não se trata de algo relacionado à cognição, nem de nada que circunde essa ideia, mas de uma realidade que apenas permite ao surdo que ele tenha acesso à modalidade escrita do português, que passaremos, a partir de agora, a chamar de português-por-escrito".

Quando o surdo brasileiro normalmente aprende o português, esta língua será para ele uma segunda língua. Sua primeira língua mais provavelmente será a LIBRAS. Entretanto, a aquisição do português normalmente acontece mediada por situações de aprendizagem formal na escola.

Nas palavras de Salles et al (2004, p.115), a modalidade a ser aprendida será o português escrito ou português-por-escrito, cujo objetivo é fazer com que o aprendente compreenda e produza textos escritos, "considerando-se os efeitos das modalidades e o acesso a elas pelos surdos".

Até pela longa tradição do ensino da língua materna, que, durante séculos, enfatizou a transmissão de informações estruturais e lexicais, poderíamos pensar desavisadamente que, na educação surda, o objetivo poderia ser o mesmo, contudo o papel dessa modalidade escrita será outra: aquela que prioriza a língua em uso, o usuário, a interação, o contexto, a intenção e seus efeitos. Dessa forma, vemos aspectos pragmáticos, sociolinguísticos e culturais serem os fatores motivadores na lide com textos, que, necessariamente, precisam ser autênticos, estar dentro dos interesses temáticos dos aprendentes e conter apelos imagéticos que provoquem a busca pela negociação de sentidos. Em outras palavras, de acordo com Salles et al (2004, p. 115), é o mesmo que dizer que:

Os textos selecionados precisam então: ser autênticos, sempre que possível; conter temas relacionados à experiência dos aprendizes, levando a um maior envolvimento

\footnotetext{
9 O ensino de português a surdos usuários de LIBRAS requer uma metodologia especializada, voltada para o português escrito ou português-por-escrito.
} 
pessoal e provocando reações e manifestações; estar associado a imagens - a boa opção seriam artigos de revistas e jornais, que costumam estar ilustrados, bem como propagandas.

Em relação ao ensino de português-por-escrito, é importante que as atividades de produção de texto, por exemplo, sejam propostas tendo um leitor real em mente. Outro aspecto que deve ser posto em relevância é a questão da internet enquanto suporte para que se deem as interações entre os usuários do português, sejam surdos - surdos, sejam surdos - ouvintes.

Por exemplo, nas salas de bate-papo, mais facilmente as negociações podem ter um caráter mais imediatista, uma vez que as trocas de turno, a não-linearidade e a presença das marcas da língua oral estão presentes. Assim, esse ambiente dialógico, de certa forma, assemelhase às interações face a face. Nesse tipo de relação dialógica, no caso, no bate-papo, há uma espécie de quebra, considerando os padrões de textos escritos mais tradicionais, como gêneros carta, bilhete, por exemplo. Para Salles et al (2004, p.116),

O diálogo constituído nessas salas constitui uma quebra em relação às trocas de
correspondências escritas tradicionais, como as cartas, pois ele possibilita um discurso
vivo por escrito, um discurso que se assemelha ao falado sob aspectos como a
dinamicidade, a temporalidade e a reciprocidade imediata. Além do mais, nele podemos
encontrar, por exemplo, as estratégias conversacionais típicas de diálogos orais, que
caracterizam a negociação de significados, conceito central na hipótese de interação.

Como já nos antecipamos em momento anterior, o oralismo se consagrou desde o Congresso de Milão, no século XIX, porém vieram outras abordagens, tais como a comunicação total. Através dessa abordagem, o sujeito surdo podia lançar mão não apenas da linguagem gestual e visual, mas também de uma espécie de leitura orofacial, possibilitada pelo uso das línguas orais, tornando-se assim um misto de todas as possibilidades de comunicação. Por fim, surgiu o bilinguismo como proposta que até os dias atuais está em pleno vigor, parecendo ser a mais acertada, e visa preservar as identidades e culturas da pessoa surda.

"Tradicionalmente, a educação de pessoas surdas esteve sob a responsabilidade da educação especial, marcada por uma visão clínica [...]”. (CAVALCANTI \& SILVA, 2007, p 223). Nessa ótica, os surdos são referenciados como deficientes, ou sujeitos "diferentes" que precisam voltar à normalidade. Certamente, por esse motivo, houve reiteradas tentativas de "apagamento dessas diferenças". (CAVALCANTI \& SILVA, 2007).

A partir da Declaração de Salamanca ${ }^{10}$, em 1994, passaram a ser reconhecidas as línguas de sinais enquanto línguas naturais pertencentes ao indivíduo surdo. Então, essa Declaração permitiu um novo olhar sobre os processos de inclusão, entre os quais cabe a reflexão sobre a educação surda numa perspectiva diferenciada do oralismo e da comunicação total.

Dessa maneira, a educação bilíngue, ou bilinguismo, é vista como solução, uma vez que permite o acesso às duas línguas no universo escolar, no caso brasileiro, a LIBRAS e o português-por-escrito. Entretanto, à língua de sinais é reservado lugar de destaque, em detrimento de outras línguas orais, pelo seu caráter de língua natural pertencente ao indivíduo surdo, partindo daí para o ensino do português escrito, na condição de língua nacional.

Trazendo um pouco da história da trajetória teórica que guiou as concepções de língua e seu ensino, podemos dizer que, desde a década de 50, cada vez mais temos nos direcionado para a questão comunicativa por excelência. Vemos que na década de 50 e 60 , imperou o Estruturalismo, que deu maior visibilidade ao Audioligualismo. Na década de 70, foi a vez do Funcionalismo, que impulsionou o Método Nocional-Funcional, aquele que alguns chamaram de precursor da Abordagem Comunicativa propriamente dita.

\footnotetext{
10 Trata-se de um documento da Organização das Nações Unidas em que se materializam os princípios, a política e as práticas ligadas à educação especial.
} 
Vemos que, a partir da década de 80, até os dias atuais, o Interacionismo tem trazido muitas contribuições para a empreitada de ensinar uma língua como ação, ou seja, nessa ótica interacionista, não temos o objetivo de ensinar metalinguagem, mas desejamos, de forma geral, ensinar os alunos a atuar no mundo por meio da linguagem e, para com ela, realizar as tarefas que lhes são peculiares como sujeitos sociais que são, partícipes de diversas situações no cotidiano que sempre envolvem outros interactantes com finalidades situadas em seus contextos reais de vida.

Diferentemente, no Estruturalismo, a língua é enxergada simplesmente como estrutura, comandando tudo. Já, no Funcionalismo, são levadas em conta as regras sociopragmáticas. Essas regras vão muito além da estrutura linguística.

O Interacionismo, por outro lado, vem trazer nova roupagem para o ensino da segunda língua. Resguardados os direcionamentos das vertentes teóricas da abordagem interacionista (a Hipótese da Interação e a Teoria Sociocultural), podemos dizer que, grosso modo, sua finalidade maior é a interação. Dessa forma, quando pensamos nesse aspecto interativo no ensino de línguas, automaticamente nos reportamos às atividades dialógicas que envolvem, no mínimo, dois interactantes; contexto real de uso; uso autêntico da língua; e como diz Brown (1994, p.81), citado por Salles et al (2004, p. 107), "produção escrita visando um público real, não um público inventado".

Isso tudo nos faz pensar no que agora passaremos a discutir na próxima seção, que é a o papel dos gêneros textuais escritos na aquisição do português por falantes surdos.

\section{Os gêneros discursivos: o que são? Para que servem?}

Os gêneros já não são objetos de estudo tão recentes. Aliás, data desde Platão sua existência, cujo teor estava diretamente ligado aos gêneros literários. Atualmente, os dois termos gêneros literários e gêneros discursivos - tratam de realidades completamente distintas. Swales (1990, p. 33) citado por Marcuschi (2008, p.147) diz que, atualmente, o "gênero é facilmente usado para referir uma categoria distintiva de discurso de qualquer tipo, falado ou escrito, com ou sem aspirações literárias".

Assim, podemos definir os gêneros, grosso modo, como textos autênticos que circulam no meio social. Dessa rápida e vaga definição depreendemos o seguinte: os textos autênticos se referem aos textos produzidos pelos usuários da língua em contextos reais de uso. É dessa maneira que pensamos em como esses gêneros discursivos escritos, e até que ponto, podem ser úteis para os aprendentes surdos do português. Outrossim, podemos dizer, segundo Marcuschi (2008), que os gêneros mostram como funciona uma sociedade.

Neste caso específico, temos o caso do português a ser aprendido por surdos, ou seja, o português-por-escrito, que nos remete automaticamente a gêneros escritos, embora que alguns deles sejam aqueles com características de gêneros orais. Nessa perspectiva, embora os gêneros tenham forma e função, é a função que os determina. Eis o motivo por que não possuem êxito os trabalhos que se dedicam exclusivamente à estrutura e à forma do gênero (BHATIA, 1997). Não é interessante que compreendamos os gêneros pelo viés da estrutura rígida, como se fosse um modelo acabado e pronto apenas. Segundo Miller (1994), citada por Marcuschi (2008, p. 151), os gêneros são formas culturais e cognitivas de ação social. De uma forma geral, achamos que o conceito de gênero por excelência que se coaduna com nossa discussão é o elaborado por Marcuschi (1992, p. 297): “(...) formas verbais de ação social relativamente estáveis realizadas em textos situados em comunidades de práticas sociais e em domínios discursivos específicos".

Muitos são os direcionamentos teóricos em relação aos estudos sobre gêneros textuais no Brasil. Em Marcuschi (2008, p. 152), encontramos algumas linhas de pensamento dentro das quais há claras tendências em relação ao tratamento dispensado aos gêneros textuais: 
1. Uma linha bakhtiniana alimentada pela perspectiva de orientação vygotskyana sociocomunicativa da Escola de Genebra representada por Schneuwly/Dolz e pelo interacionismo sociodiscursivo de Bronckart. Essa linha de caráter essencialmente aplicativo ao ensino de língua materna é desenvolvida particularmente na PUC/SP.

2. Perspectiva swalesiana, na linha da escola norte-americana mais formal e influenciada pelos estudos de gêneros de John Swales (1990) tal como se observa nos estudos da UFC, UFSC, UFSM e outros polos.

3. Uma linha marcada pela perspectiva sistêmico-funcional é a escola australiana de Sydney, alimentada pela teoria sistêmico-funcionalista de Halliday com interesses na análise linguística dos gêneros e influente na UFSC.

4. Uma quarta perspectiva menos marcada por essas linhas e mais geral, com influências de Bakhtin, Adam, Bronckart e também os norte-americanos como Charles Bazerman, Carolyn Miller e outros ingleses e australianos como Günther Kress e Norman Fairclough, é a que se vem desenvolvendo na UFPE e UFPB.

Até por uma questão de pertinência, considerando a discussão que estamos fazendo, nos afiliamos à última tendência, por tratar principalmente dos gêneros como atividade e como ação social. Não faremos menção a todos os autores citados anteriormente. Serão nossas referências, principalmente, Bakhtin (1992), Bazerman (2006) e Miller (1994).

Escolhemos Bakhtin (1992), pelo fato de seu pensamento inspirar a escola norteamericana, ou seja, autores como os dois últimos, que nos auxiliam bastante para compreender melhor o papel dos gêneros textuais escritos na aprendizagem do português por surdos. Bakhtin volta a compreensão para a questão sócio-histórica e dialógica dos gêneros, além de conceber que as atividades humanas, de uma forma ou de outra, estão relacionadas ao uso da língua, que é viabilizado/concretizado por meio de enunciados (MARCUSCHI, 2008). Em outras palavras, é dizer que os gêneros são “(...) tipos relativamente estáveis de enunciado” (BAKHTIN, 1992, p.297).

Quando falamos no "uso da língua" acima, necessariamente nos reportamos a Antunes (2005, p.30), que diz:

\footnotetext{
Ninguém fala ou escreve por meio de palavras ou de frases justapostas aleatoriamente, desconectadas, soltas, sem unidade. O que vale dizer: só nos comunicamos através de textos. Sejam eles orais ou escritos. Sejam eles grandes, médios ou pequenos. Tenham muitas, poucas, ou uma palavra apenas. Assim, a competência comunicativa, aquela que nos distingue como seres verbalmente atuantes, inclui necessariamente a competência para formular e entender textos.
}

No que diz respeito a Bazerman (2006), salientamos a questão do gênero enquanto atividade social. Para contextualizar melhor essa linha de pensamento, devemos admitir a existência de três concepções sobre a construção do significado que permeia o texto, ou que está no seu entorno.

A primeira e mais tradicional faz referência aos significados, como se eles estivessem no próprio texto. A segunda tem a ver com a interação entre escritor e texto e/ou leitor e texto. Já a última, a que nos orienta nesta discussão, lida diretamente com os significados sendo criados a partir da interação entre o escritor e o leitor, tendo como mediação o texto, seja oral seja escrito. Esses textos (ou gêneros) “(...) tipificam muitas coisas além da forma textual. São parte do modo como os seres humanos dão forma às atividades sociais" (BAZERMAN, 2006, p. 31).

Nessa medida, quando nos deparamos com o objeto desta discussão, que é o papel dos gêneros textuais na aprendizagem do português escrito por surdos, entoamos uma realidade muito clara de interação entre esses usuários do português no momento em que eles lançam mão dos gêneros criados pela onda tecnológica dos últimos anos, mais precisamente, o bate-papo e o SMS, como exemplos. 
O momento atual é prenhe de novidades tecnológicas que fomentam possibilidades de interação entre os falantes surdos, usando o português, como jamais vimos antes. Nesse dizer, é inevitável pensarmos num ensino de português para esses sujeitos que estejam necessariamente vinculados ao uso de gêneros como esses. Vislumbramos aqui apenas os dois (bate-papo e SMS), propositalmente, como uma forma dicotômica de, em um, vermos satisfeitas as suas necessidades interacionais com características de produção que mais se assemelham aos gêneros orais, como é caso de ouvintes. Já o outro exemplifica a moda que toma conta não apenas da educação linguística surda, mas de todos os aprendentes do português. Porém, para o surdo, o papel desse gênero translada para a sua realidade circundante a possibilidade quase que exclusiva de interagir e vivenciar as nuanças todas de quem está envolvido nas atividades socialmente situadas, normalmente inviabilizadas pela surdez. Assim, podemos dizer que eles produzem esses textos para "realizar os vários trabalhos no mundo", conforme fala Bazerman (2006, p. 51).

Nesse sentido, cabe dizer que o papel desses gêneros, sem dúvida alguma, é de tornar esses sujeitos capazes de transitar num mundo pluricentricamente letrado, misturado de semioses, no qual eles podem perfeitamente estar inseridos não como fazendo parte da estatística de excluídos, mas como interactantes autônomos, conscientes de suas limitações ${ }^{11}$, porém autorizados a atuarem em espaços de letramentos que, não há muito tempo, eram exclusivos dos ouvintes.

Aqui cabe referirmo-nos à questão do gênero como ação social. Para Miller (1994), o gênero é muito mais que uma entidade formal. Ele é pragmático em sua essência, tendo como corolário a relação intenção/efeito, um aspecto claro da ação social engendrada nos espaços em que o surdo utiliza o português para se comunicar em dimensões públicas e privadas, com intenções diversas, causando paralelamente os efeitos consecutivos: escrever para comunicar, reclamar, expressar afeto, pedir esclarecimentos, por exemplo; ler para ter acesso a notícias e informações quaisquer, entre tantas outras. Trata-se, indiscutivelmente, de conceber a linguagem enquanto ação.

O esquema cíclico do gênero textual nos proporciona entender que ele nasce, evolui, muda e desaparece, dependendo da complexidade e peculiaridades da sociedade em que eles transitem. No caso dos surdos com o português, a situação não é diferente. Estamos lançando mão dos referidos gêneros como exemplos (bate-papo e SMS), não como únicas possibilidades de gêneros digitais ou não a serem aprendidos, tampouco trazemos uma lista exaustiva promulgando receitas finitas de como a língua deve ser ensinada. Nossa intenção é tão-somente provocar uma discussão que traga uma prática concebendo a língua/linguagem nestes termos: "A linguagem é uma atividade social, é um ato histórico, político, cultural, que envolve um complexo conjunto de habilidades (cognitivas, textuais e interativas) e de fatores situacionais". (ANTUNES, 2005, p. 21)

Como já dissemos, achamos que o ensino da língua portuguesa para os surdos é de extrema necessidade, sobretudo se pensarmos que essa não é sua primeira língua, mas a língua da Nação onde eles vivem.

Assim, dadas as dificuldades naturais que encontramos todos, sejamos surdos sejamos ouvintes, para aderir a um universo de ensino de línguas em contextos extremamente tradicionais ${ }^{12}$ que não nos oportunizam uma aprendizagem eficaz, isto é, de como usar essa língua em contextos reais, vemos especificamente no ensino do português-por-escrito, através dos gêneros, uma forma de maior engajamento dos aprendentes surdos, tendo em vista que essa aprendizagem surtirá efeitos muito práticos, ou seja, o manuseio produtivo ou receptivo deles

\footnotetext{
11 As limitações são apenas consideradas tendo como referência o ouvintismo.

${ }^{12}$ Referimo-nos às metodologias tradicionais que impunham tão-somente o ensino da estrutura linguística, como se aprender aspectos formais da língua exclusivamente desse conta de nos tornar capazes de lidar com as situações diversas que se apresentam dia a dia, seja produzindo seja recebendo esses artefatos de linguagem que circulam em nosso meio social.
} 
fará com que os surdos se tornem sujeitos mais ativos, autônomos e muito mais hábeis cognitiva, textual e interativamente nas negociações de sentido que emergem nos intercâmbios linguísticocomunicativos que se interpõem em suas vidas como sujeitos sociais plenos que são.

\section{CONSIDERAÇÕES FINAIS}

Finalmente, podemos dizer que a aquisição da língua portuguesa por meio dos gêneros textuais não é algo que começou de uns dias para cá, mas muito precisa ainda ser feito para que essa concepção se torne presente nas práticas diuturnas do universo escolar, tanto de ouvintes, quanto de surdos. Em relação a estes últimos, trazemos de maneira mais incisiva algumas implicações:

A questão intercultural é algo que precisa ser revista, principalmente quando o foco são os gêneros digitais para a realidade da educação linguística surda. Isso quer dizer que, ao analisarmos a situação de ensino de surdos baseada nesses gêneros (bate-papo e SMS), devemos atentar para a questão cultural, tendo em vista que para a(s) cultura(s) surda(s), os gêneros digitais não têm a mesma circulação situacional que para os ouvintes, como uma possibilidade a mais. Enquanto para o universo dos ouvintes, a escolha entre um gênero ou outro se dá em função meramente de adequação situacional ou preferência pessoal, no caso dos surdos, a escolha desse ou daquele gênero se faz de forma quase que imperativa. Eles, por exemplo, não podem optar por um diálogo face a face, na utilização do português oral.

Há ainda outras questões a serem abordadas como, por exemplo, a forma como esses gêneros se estruturam e como são instrumentalizadas suas funções. Devemos compreender que a heterogeneidade cultural permite as variações existentes em quaisquer sociedades, as quais podem figurar como problema para alguns desavisados. Estes $^{13}$, via de regra, tendem a prescrever regras fixas de uso e circulação desses gêneros, sem respeitar as particularidades e os fatores identitários presentes em cada indivíduo, independentemente de serem surdos ou não.

No que diz respeito aos gêneros bate-papo e $S M S$, podemos pontuar também outros aspectos que transbordam a questão da ortografia, da pontuação, das estruturas frasais menos comuns para o português ouvinte, sinalizando a emergência de um horizonte para o qual há pertinência de uma discussão (ou de discussões!) que envolva múltiplos letramentos e o mundo multissemiótico ${ }^{14}$ na educação linguística surda, tendência quase inconteste no universo hipertextual em que vivemos todos hoje.

Por último, mas não menos importante, tocaremos em um assunto que necessariamente não precisa ser abordado dentro do quadro da episteme científica, mas na ambientação da experiência vivencial dos indivíduos que fazem a educação neste País.

Estamos nos referindo ao altruísmo, à forma mais autêntica de contemplar a alteridade que nos constitui tão complexamente como seres humanos. Parece-nos que, em muitas situações, podemos promover um diferencial nas vidas das pessoas. No caso de quem milita na educação surda, mais sensibilidade e dedicação devem ser dispensadas em cada reflexão e prática em prol desses sujeitos tão estigmatizados ao longo da história. Esse diferencial de que falamos se refere à implantação de esperança por um mundo melhor, sem desigualdades, com mais oportunidades para todos nós que constituímos essa massa amorfa e tão plural que é a humanidade: surdos, ouvintes, mulheres, homens, crianças, negros, braços, índios, imigrantes, homossexuais...

\footnotetext{
13 Aqui, pensamos nas situações hipotéticas em que professores de português sem formação adequada podem equivocadamente exigir a produção de gêneros dentro de padrões fixos e com tamanha rigidez a ponto de desrespeitar as características dos surdos, como concebem o mundo em sua volta e as relações que estabelecem com a língua portuguesa enquanto segunda língua, tendo como referência a língua de sinais, sua primeira língua. Referimo-nos, nesse tocante, às questões, sobretudo, ligadas à forma linguística e suas funções.

${ }^{14}$ Conforme Rojo (2008, p. 91), o mundo multissemiótico pode ser entendido "para além da letra, ou seja, um mundo de cores, sons, imagens e design que constroem significados em textos orais / escritos e hipertextos".
} 


\section{REFERÊNCIAS BIBLIOGRÁFICAS}

AGRELLA, Regiane Pinheiro. Língua, Subjetividade e Opressão Linguística: Interrogações a uma Pedagogia Surda. Dissertação de mestrado (Educação). Campinas: UNICAMP, 2010.

ANTUNES, Irandé. Lutar com palavras: coesão e coerência. São Paulo: Parábola Editorial, 2005.

BAKHTIN, M. Os gêneros do discurso. In: BAKHTIN, M. Estética da Criação Verbal. Tradução M. E. G. Gomes. São Paulo: Martins Fontes, 1992 [1953]

BARBOSA, Elomena Barbosa de. O papel de professores surdos e ouvintes na formação do tradutor e intérprete de Língua Brasileira de Sinais, Dissertação de Mestrado. UNIMEP. Ano de Obtenção: 2010.

BAZERMAN, Charles. Gêneros textuais, tipificação e interação. In: BAZERMAN, Charles;

DIONÍSIO, Ângela Paiva; HOFFNAGEL, Judith Chambliss (Orgs.). $2^{a}$ ed. São Paulo: Cortez, 2006.

BHATIA, V. K. Genre Analysis Today. Revue Belge de Philologie et d'Histoire. 75 (3), 629652, 1997.

BROWN, H. D. Principles of language learning and teaching. San Francisco: Prentice Hall, 1994.

CAMPELLO, Ana Regina e Souza. Aspectos da visualidade na educação de Surdos. Tese de Doutorado (Educação). Santa Catarina: Universidade Federal de Santa Catarina, 2008.

CAVALCANTI, Marilda C.; SILVA, Ivani Rodrigues. "Já que ele não fala, podia ao menos escrever...": o grafocentrismo naturalizado que insiste em normalizar o surdo. In: KLEIMAN, Ângela B.; CAVALCANTI, Marilda C. (Orgs.). Linguística Aplicada: suas faces e interfaces. Campinas, SP: Mercado de Letras, 2007.

GESSER, Audrei. Libras? Que língua é essa?: crenças e preconceitos em torno da língua de sinais e da realidade surda. São Paulo: Parábola Editorial, 2009.

GRANNIER, Daniele Marcelle. A jornada linguística do surdo da creche à universidade. In:

KLEIMAN, Ângela B.; CAVALCANTI, Marilda C. (Orgs.). Linguística Aplicada: suas faces e interfaces. Campinas, SP: Mercado de Letras, 2007. 
HAHN, Rosimêri Schuck Schmidt. Diálogos sobre a escola e a educação bilíngue Libras/Português: olhares de surdos e ouvintes. 2012. 211 p. Dissertação (mestrado) Universidade Estadual de Campinas, Faculdade de Educação, Campinas, SP.

McCLEARY, Leland Emerson. O ensino de língua estrangeira e a questão da diversidade. In:

LIMA, Diógenes Cândido de (Org.). Ensino e aprendizagem de Língua Inglesa: conversas com especialistas. São Paulo: Parábola Editorial, 2009.

MARCUSCHI, Luiz Antônio. Produção textual, análise de gêneros e compreensão. São Paulo: Parábola Editorial, 2008.

MILLER, C. R. Genre as a social action. In: Freedman, A. \& Medway, P. (Orgs.). Genre and the new rhetoric: London: Taylor \& Francis, 1994.

NASCIMENTO, Gláucia Renata Pereira do. Aspectos da organização de textos escritos por universitários surdos. 2008. 235 f. Tese (doutorado em Letras/Linguística). Curso de PósGraduação em Letras, Universidade Federal de Pernambuco, Recife, 2008.

ONU. Declaração Universal dos Direitos Humanos. Disponível em: $<$ http://unicrio.org.br/img/DeclU_D_HumanosVersoInternet.pdf $>$. Acesso em: 02 de agosto de 2013.

ROJO, Roxane. Gêneros de discurso/texto como objeto de ensino de línguas: um retorno ao trivium?. In: SIGNORINI, Inês. [Re]discutir texto, gênero e discurso. São Paulo: Parábola Editorial, 2008.

SALLES, Heloísa M. M. Lima; FAULSTICH, Enilde; CARVALHO, Orlene Lúcia; RAMOS, Ana A. Lopo. Ensino de língua portuguesa para surdos: caminhos para a prática pedagógica. Brasília: MEC, SEESP, 2004.

SWALES, J. M. Genre Analysis: English in Academic and Research Settings. Cambridge: Cambridge University Press, 1990. 